\title{
Mais que apenas ver: a leitura on-line em língua espanhola por deficientes visuais
}

\author{
MÁS QUE SOLAMENTE VER: LA LECTURA EN LÍNEA EN LENGUA \\ ESPAÑOLA POR DISCAPACITADOS VISUALES
}

\section{Marcus Vinícius Liessem FONTANA *}

Resumo: Este artigo discute o processo de leitura, em especial de leitura em espanhol como língua estrangeira, no âmbito do processo de ensinoaprendizagem de deficientes visuais em ambiente digital. Iniciando por uma rápida explicação sobre os diferentes tipos de deficiência visual e sobre as tecnologias atualmente disponíveis para este público, chega-se a um debate sobre a atividade de leitura, traçando-se diferenças entre a forma como videntes e não videntes a realizam. Este debate desemboca no processo de criação de um curso de leitura on-line de espanhol para deficientes visuais e dos resultados positivos obtidos com esta iniciativa, levando a projeções sobre novas possibilidades de encontro entre ensino de línguas estrangeiras e deficiência visual.

Palavras-chave: Deficiência visual; Ensino mediado por computador; Ensino de línguas estrangeiras.

Resumen: Este artículo discute el proceso de lectura, en especial de lectura en español como lengua extranjera, en el ámbito del proceso de enseñanzaAprendizaje de discapacitados visuales en ambiente digital. Empezando por una rápida explicación sobre los distintos tipos de discapacidad visual y sobre las tecnologías actualmente disponibles para este público, se llega a un debate sobre la actividad de lectura, diseñándose diferencias entre las formas como videntes y no videntes la realizan. Este debate lleva al proceso de creación de un curso de lectura en línea de español para discapacitados visuales y de los resultados positivos que se obtuvieron con esta iniciativa, llevando a proyecciones sobre nuevas posibilidades de encuentro entre enseñanza de lenguas extranjeras y discapacidad visual.

\footnotetext{
* Mestrado em Letras - Linguística Aplicada pela Universidade Católica de Pelotas. Professor Assistente da Universidade Federal de Santa Maria. Contato: marcusvfontana@yahoo.com.br.
} 
Palabras-clave: Discapacidad visual; Enseñanza mediada por computadora; Enseñanza de lenguas extranjeras.

\section{Introdução}

"A leitura nutre a inteligência" dizia o velho Sêneca, e é possível que tenha elaborado este enunciado partindo de sua própria experiência de vida. Homem de livros, Sêneca foi um expoente em sua época: literato, dramaturgo e filósofo, cuja inteligência o levou a tornar-se preceptor do próprio imperador romano, à época, Nero. Infelizmente, nem toda a sua inteligência foi capaz de sublimar o gosto deturpado que o monarca nutria pelo sangue alheio, tampouco de salvar sua própria vida quando, horrorizado pelas ações do imperador, uniu-se a um grupo de insurgentes que fracassou em sua tentativa de golpe. Seja como for, esta pequena digressão serve para percebermos a importância tão grande que há milênios se dá à leitura. A exemplo de Sêneca, inúmeras figuras de fundamental importância histórica tocam no tema, falando da leitura de maneira apaixonada. Mais além da paixão, as próprias ciências linguísticas da atualidade se encarregam de abordar o tema de maneira, diria, mais objetiva, demonstrando não apenas sua importância, mas buscando desvendar seus processos.

O tempo, é óbvio, se encarregou de ir transformando a maneira como encaramos a leitura, sobretudo do texto escrito. Desde os antigos signos representados em pedra, passando pelos papiros e pela invenção da imprensa, muita coisa mudou. Hoje, temos ao nosso alcance o hipertexto, que transformou radicalmente a maneira como se dá a leitura. A nova geração, o homo rappiens (VEEN; VRAKKING, 2009), aquelas crianças que praticamente nasceram com um teclado sob os dedos e um monitor diante dos olhos, percebem o texto de uma maneira quase quadridimensional (no sentido einsteiniano de que o tempo é a quarta dimensão): o espaço físico é transcendido de tal forma que textos diversos espalhados pelo globo se interpenetram e se complementam formando um todo de sentido que lhes permite ir muito além do que antes nos permitia a página impressa. Com um simples clique do mouse o leitor é transportado daqui para lá, em uma viagem fantástica de conexões e inter-relações antes impensáveis. A 
leitura linear de um texto, para esta geração, é algo quase mítico, uma impossibilidade.

Quando tratamos de leitura, entretanto, em geral nos remetemos ao valioso e fascinante sentido da visão. Pensar a leitura, em geral, significa partir do princípio de que estou enxergando. As letras impressas sobre o papel, as tintas multicoloridas que se unem e assumem formas que comunicam... isso só pode ser percebido porque tenho olhos para ver... e se não os tivesse?

Essa, em parte, tem sido minha preocupação nas pesquisas que tenho desenvolvido ao longo dos últimos dois ou três anos. Especialmente, preocupa-me o processo de aprendizagem de deficientes visuais. Como se dá esse processo sem a preciosa capacidade de ver? Que recursos, que estratégias estudantes com este tipo de dificuldade utilizam para obter resultados positivos em seus esforços por aprender? Estas preocupações me levaram a um dos meus projetos de pesquisa atuais, em que procuro desenvolver os recursos necessários para que estudantes com deficiência visual possam aprender, on-line, a língua espanhola. Trata-se de uma iniciativa que desembocará em um curso de extensão e que, quem sabe, no futuro poderá servir como base para um curso de graduação nesta área. Muito antes disso, entretanto, minhas inquietações me levaram, no ano 2008, a desenvolver um curso de leitura em língua espanhola on-line para deficientes visuais. A intenção era criar um espaço de ensino e pesquisa que servisse para entender melhor esses processos e que funcionasse como trampolim para, mais adiante, elaborar um curso que pudesse contemplar as quatro habilidades linguísticas: leitura, escrita, compreensão auditiva e interação oral (GIOVANNINI et al., 1996).

Aqui, entretanto, procuro deter-me na discussão de como funciona o processo de leitura on-line para pessoas com deficiência visual. Quais reflexões e quais práticas foram necessárias para chegar a um bom resultado no desenvolvimento de um curso deste tipo? Em primeiro lugar, porém, quero definir com o máximo de clareza possível o que é deficiência visual e traçar um rápido panorama dos recursos tecnológicos que hoje estão disponíveis para este público. 


\section{Quem são os que não veem?}

O senso comum nos diz que deficiente visual é aquela pessoa que não enxerga absolutamente nada, ou seja, o cego. Mon (1998) explica que, na verdade, a expressão deficiência visual (discapacidad visual, em espanhol) inclui dois aspectos possíveis: a cegueira e a baixa visão. Mesmo a cegueira pode ser caracterizada de duas formas: a cegueira total ou visão zero, em que não se diferencia entre luz e escuridão, e a cegueira grave ou quase total, em que há a mínima percepção das variações de luz.

Com relação à baixa visão ou visão subnormal, temos aí incluídas as pessoas que apresentam apenas $3 / 10$ da visão normal ou que possuem um campo visual menor ou igual a 20 graus. Para que se possa entender este conceito, é importante saber que "la agudeza normal es de 10/10 mientras que los límites del campo visual son $90^{\circ}$ en la parte externa o temporal, $60^{\circ}$ en la interna o nasal, $50^{\circ}$ en la parte superior y $70^{\circ}$ en la inferior" (MON, 1998). Disto se pode depreender que, apesar de possuírem grandes dificuldades, as pessoas de baixa visão ainda conseguem recorrer a este sentido para realizar várias de suas tarefas cotidianas, muito embora possam necessitar de iluminação especial, lentes ou outros aparatos para isso.

Esta diferenciação entre pessoas cegas e pessoas de baixa visão é de indiscutível importância quando se fala de educação mediada por tecnologias para deficientes visuais, pois as tecnologias que atendem aos de baixa visão muitas vezes podem não atender aos cegos, enquanto, em contrapartida, algumas tecnologias voltadas para pessoas cegas podem ser desnecessárias a pessoas de baixa visão. O processo de ensino-aprendizado de pessoas realmente cegas deve privilegiar, sobretudo, o tato e a audição. Isto não significa, entretanto, que os cegos não tenham condições de aprender ou que seu aprendizado seja inferior ao dos videntes ou normovisuais. O que temos, sim, são maneiras diferentes de aprender e de perceber o mundo. É interessante notar, ainda, que o conceito amplamente difundido de que a natureza se encarrega de compensar a cegueira desenvolvendo os demais sentidos da pessoa cega não passa de mito. O que ocorre, de fato, é que o cego se vê na contingência de colocar em atividade intensa seus outros sentidos e todos os bons resultados que venha a alcançar não são mais que produto de uma prática exaustiva e disciplinada. 


\section{Tecnologias para deficientes visuais}

O surgimento de sistemas operacionais com interface prioritariamente visual, como o Microsoft Windows e similares, acabou por criar uma barreira de exclusão para cegos e pessoas com deficiência visual grave. O que para muitos se mostrou como uma evolução e uma maneira mais intuitiva de interagir com o computador, para esta minoria delineou-se como um obstáculo ainda mais grave para o acesso ao mundo da computação e a todas as suas possibilidades. Se já era difícil ter acesso ao mundo informatizado à época, devido aos altos preços e, sobretudo, aos recursos limitadíssimos da tela negra do sistema operacional DOS, com o Windows, qualquer interação se tornou impossível.

Com o tempo, porém, um movimento em sentido oposto acabou tomando força. Muitos pesquisadores, conscientes das dificuldades pelas quais passam os deficientes visuais, decidiram investir esforços na criação de meios de acesso para este público. Carvalho (2001) menciona vários dispositivos e softwares que foram e estão sendo desenvolvidos com o intuito de facilitar aos deficientes visuais o acesso à informação e isso inclui o computador e a Internet. $\mathrm{O}$ pesquisador ainda separa estes dispositivos entre os que atendem exclusivamente às pessoas de baixa visão e aqueles que também são adequados para pessoas com perda total de visão. Entre os meios voltados para pessoas com baixa visão, temos, por exemplo, ampliadores de tela, que são basicamente softwares utilizados para ampliar as fontes das letras visualizadas na tela, e lentes e lupas para ampliação de textos. Entre os meios voltados para pessoas cegas, os principais são os softwares sintetizadores de voz, programas capazes de ler textos diretamente da tela do computador, reproduzindo-o por meio de alto-falantes ou fones de ouvido.

Para pesquisadores como Santarosa e Sonza (2003), os softwares sintetizadores de voz, entre os quais citam o DOSVOX, o VIRTUAL VISION e o JAWS, apresentam um potencial inclusivo muito grande, pois abrem novas janelas para as pessoas com necessidades especiais, rompendo com a "lógica racionalista excludente" ao se mostrarem poderosas ferramentas de pesquisa, aprendizagem, busca de informações e, portanto, interação com o mundo. Fontana e Vergara 
Nunes (2005) advertem, entretanto, que muitos deficientes visuais sentem-se incomodados com a leitura mecânica e formal realizada por alguns sintetizadores de voz presentes no mercado. A clássica voz robotizada, que em muitos casos lembra mais o assustador vilão de Guerra nas Estrelas que a comunicação humana, pode tornar-se um empecilho para o bom entendimento de um texto ou, pelo menos, pode minorar o prazer da leitura, tornando-a cansativa e monótona. Não se pode esquecer, porém, que a tecnologia avança a passos largos e que a tendência é que os sintetizadores de voz apresentem cada vez mais as características próprias da voz humana.

Essas leituras abriram espaço para importantes reflexões sobre os recursos que seriam necessários para alcançar bons resultados em um curso de leitura on-line para deficientes visuais. Ainda assim, a experiência prática, presenciar a interação de um deficiente visual com o computador parecia imprescindível para conhecer melhor o terreno. Com isso em mente, procurei um ambiente onde tivesse a oportunidade de testemunhar pessoalmente essa relação deficiente visual-máquina. A oportunidade surgiu na Escola Louis Braille.

\section{Um brevíssimo estudo de caso: a Escola Louis Braille de Pelotas}

Leffa (2006) sugere a pesquisa qualitativa como um método fundamental nos estudos que envolvem o ensino mediado por computador o que, entendo, adquire ainda mais relevância quando se trata de um grupo minoritário. Como se sabe, diferente da pesquisa quantitativa, a qualitativa se atém a pontos específicos e pessoais, procurando interpretar não apenas números, mas os sentimentos e as impressões dos indivíduos envolvidos na pesquisa. Desta forma, optei pela realização de uma pesquisa menos extensa, envolvendo a realidade de um grupo específico de alunos pertencentes à Escola Louis Braille da cidade de Pelotas, Rio Grande do Sul, escola esta voltada especialmente ao atendimento de pessoas com diferentes níveis de deficiência visual, muito embora atenda a pessoas com outros tipos de deficiência. A escola possui um sistema formal de ensino que contempla crianças deficientes visuais de pré-escola e de $1^{\mathrm{a}}$ a $4^{\mathrm{a}}$ séries do Ensino Fundamental, mas também oferece acompanhamento a adolescentes e adultos, além de dar apoio e orientação a familiares. 
Em sua grade curricular, a disciplina de Informática era ministrada, inicialmente, como optativa a partir da $3^{\text {a }}$ série. Atualmente, porém, é disciplina obrigatória desde a pré-escola. Apesar disso, segundo uma das professoras, há considerável dificuldade para encontrar programas de computador adequados às crianças e que colaborem com seu processo de aprendizagem. Relativamente poucos, por exemplo, são os jogos educativos que podem ser utilizados por crianças deficientes visuais, especialmente porque a sonorização destes jogos muitas vezes não é significativa, quesito indispensável para este público. Ainda assim, apesar das restrições, há algumas boas alternativas, como o caso de um jogo de tabuada em que o aluno escuta uma comemoração de gol toda vez em que acerta uma conta. A aprendizagem da tabuada por meio do jogo tem se mostrado bastante motivadora e tem trazido resultados muito positivos.

Quanto ao grupo que acompanhei por um breve espaço de tempo, era formado por três alunos deficientes visuais adultos que estavam aprendendo a manejar o computador por meio da digitação de textos com o apoio do sistema operacional DOSVOX, munido de sintetizador de voz. Dois destes alunos eram cegos e o terceiro tinha baixa visão. As aulas eram ministradas por uma professora vidente com cerca de dez anos de experiência no ensino a deficientes visuais. Todos os três alunos utilizavam computadores pessoais comuns, com a única diferença de ter o mencionado DOSVOX instalado. Para a digitação de texto, contavam com teclados de tipo padrão, dos mais simples encontrados em qualquer loja. Note-se que um requisito da fabricação de qualquer teclado moderno, exigido pela ABNT, é que ele possua marcas em alto relevo nas teclas $f$ e $j$. Estas marcas indicam a posição de teclado que devem assumir os dedos indicadores de ambas as mãos. Com a prática e a correta instrução, os deficientes visuais conseguem memorizar a posição das teclas e utilizar o teclado como qualquer digitador experiente o faz. Para acompanhar a correção do que está sendo digitado, os alunos contam ainda com fones de ouvido para escutar a resposta do sintetizador de voz a sua ação.

Ao longo do trabalho de observação, pude perceber que, apesar de um tanto mecânica, a voz sintetizada do editor de texto do DOSVOX, o EDIVOX, dá condições bastante razoáveis para a leitura e para a escrita de textos. A leitura é feita linha por linha de maneira 
mais ou menos fluente e, em geral, se criam as condições necessárias para que os alunos compreendam o que está escrito. Quanto à escrita, há alguns recursos interessantes. Como exemplo, cito o fato de que o processador de texto sintetiza voz feminina quando as letras são minúsculas e voz masculina quando as letras são maiúsculas, o que permite um acompanhamento suficientemente preciso.

A observação permitiu-me evidenciar que os alunos "lêem" textos simples sem maiores dificuldades. A escrita, entretanto, é bastante lenta. Ainda que não seja o objetivo neste texto, parece-me interessante mencionar que em uma das aulas, de 45 minutos, por exemplo, meus três observados conseguiram digitar cerca de duas linhas de um texto infantil bastante simples. Isto se deve, possivelmente, a sua inexperiência, pois cometiam muitos erros e a professora precisava atendê-los um a um, fazendo-os refletir sobre os motivos de seus erros e orientando a correção. Não poucas vezes a professora foi obrigada a recolocar os dedos dos alunos sobre o teclado, pois eles se perdiam e não conseguiam mais encontrar a posição correta. Interessante, neste ponto, notar a paciência e a didática da professora. Para um dos alunos, com troca recorrente na digitação das letras $i$ e $o$, ela passou repetidas vezes seu dedo indicador sobre o anular direito do aluno, pousado sobre a tecla l, dizendo: "Esse é o dedo do 'o'. Memoriza isso. Ele tem que subir pro 'o"'. Esta estimulação tátil pareceu surtir efeito imediato, pois o aluno conseguiu fixar a posição correta e digitar acertadamente daí para frente.

Apesar de todas as dificuldades, entretanto, chama a atenção o ânimo dos alunos e a boa vontade da professora. Não há dúvidas, pelas observações feitas, de que o trabalho é extremamente exaustivo, porém os resultados são compensadores. Tive a oportunidade de conhecer usuários de computador avançados mais tarde e sua habilidade, tanto em leitura como em escrita mediadas por computador, se assemelha bastante à de qualquer normovisual. Vejamos, entretanto, algumas diferenças gerais entre estes dois grupos (normovisuais e deficientes visuais) no que tange à leitura e o tipo de reflexão que é necessária para se desenvolver um trabalho eficiente neste âmbito em atividades mediadas por computador. 


\section{Espanhol on-line para deficientes visuais: algumas reflexões e escolhas}

Quando pensei em elaborar um curso de espanhol para aprender mais sobre o processo de ensino-aprendizagem de deficientes visuais diante da Internet, ainda não tinha claro que seria um curso de leitura. Houve, porém, uma questão fundamental que norteou todas as escolhas que mais adiante foram feitas: que enfoque poderia, ao mesmo tempo, ser suficientemente significativo para um primeiro contato de deficientes visuais com a língua espanhola e de prática implementação por meio dos recursos disponíveis na Internet para esse público?

A primeira luz lançada sobre essa questão veio de Salager-Meyer \& Ulijn (1998). Para os autores, o processo da aprendizagem depende em grande parte de informações derivadas de textos, o que significa dizer que a habilidade da leitura é fundamental tanto para o desenvolvimento acadêmico do estudante, de maneira geral, como para o domínio de qualquer língua estrangeira. Paiva (2000), apesar de defender a abertura de um maior espaço para a oralidade nos cursos de língua estrangeira, admite que "a leitura é um dos componentes mais relevantes no ensino de uma LE" e narra que em pesquisa realizada com "alunos bem sucedidos" do curso de Letras da Universidade Federal de Minas Gerais (UFMG), em 1994, "a estratégia individual de aprendizagem mais utilizada por esses aprendizes é a leitura". Paraquett (2001), por sua vez, aborda a aprendizagem de uma língua estrangeira como um processo de autodescobrimento em que o estudante busca conhecer o outro para se conhecer melhor e afirma que essa busca deve ser pautada especialmente na formação de leitores. Outro autor que contribui para dar ênfase à importância da leitura como instrumento de aprendizagem de uma língua estrangeira é João Sedycias que afirma, especificamente em relação ao idioma espanhol, que:

Considerando a competitividade do mercado e a necessidade de atualização constante de informações científicas e tecnológicas e as dificuldades das traduções de artigos, livros e outras publicações em tempo hábil, ou seja, com a mesma velocidade em que são escritos, muitas universidades brasileiras - seguindo 
mudanças similares no ensino do inglês - resolveram mudar o enfoque do ensino de espanhol como língua estrangeira, passando do estudo sistemático de vocabulário e regras gramaticais para um estudo mais abrangente de textos autênticos retirados das próprias fontes de informação. (SEDYCIAS, 2002)

A partir dos conceitos desses autores, decidi que a melhor opção seria o uso de textos autênticos em língua espanhola para a construção de um pequeno curso introdutório ao idioma. As unidades didáticas seriam desenvolvidas, portanto, no sentido de estimular e desenvolver as habilidades de leitura na língua alvo, o que poderia ser classificado como um curso de leitura instrumental. Como explica Sedycias (2002), entretanto, um curso de língua espanhola instrumental sempre tem em vista as necessidades dos estudantes. Uma pessoa da área de Informática, por exemplo, necessitará trabalhar com textos afins para alcançar seus objetivos, o mesmo que um médico ou um advogado. $\mathrm{O}$ que reuniria os estudantes em torno do curso que se estava planejando, entretanto, não eram questões acadêmicas ou profissionais, mas o fato de que eles teriam em comum a deficiência visual.

Que necessidade básica poderia ser sanada por meio de um curso como o que pretendia? Como o público seria, possivelmente, bastante variado, abracei a ideia de utilizar gêneros textuais diferentes para cada uma das unidades didáticas. Imaginei que assim seria possível colocar o estudante em contato com a gama mais ampla possível de informações, posição que é encorajada por Penny Ur (1996). Essa ideia baseou-se, também - e, talvez, principalmente -, no fato de que o suporte do curso seria a Internet e que, portanto, se supunha que os estudantes seriam usuários relativamente hábeis da rede mundial de computadores; pessoas acostumadas a navegar por diferentes páginas, com diferentes conteúdos e variados enfoques; pessoas que provavelmente utilizariam a web não apenas para obter informações, para pesquisar, mas também para se comunicar com outras pessoas e para entretenimento. Em suma, pessoas acostumadas, em certa medida, com a fragmentação da informação contida na rede e habituadas a explorar o espaço cibernético, com seus múltiplos enlaces, conscientes de que em dado momento é possível estar lendo uma notícia em um jornal on-line e ser remetido, pelo simples ato de clicar em algum link, a 
um artigo acadêmico, a uma poesia ou a uma anedota, assumindo o que Veen \& Vrakking (2009) chamam de "comportamento não-linear", característica adquirida por quem tem que aprender a lidar com o hipertexto, a pedra fundamental sobre a qual está assentada atualmente a rede mundial de computadores.

Evidentemente, essa suposição inicial foi colocada à prova ao longo do estudo e pude verificar que, apesar de a maioria dos alunos realmente ter habilidades bastante desenvolvidas, alguns alunos demonstraram um pouco mais de dificuldade, o que é absolutamente natural. Sobre o hipertexto, de maneira simplificada, pode-se dizer que é "algo que está numa posição superior à do texto, que vai além dele" (RAMAL, 2002). Isso porque o hipertexto tem características que transcendem o texto impresso, linear, preso a um formato estanque. Para Pierre Lévy (1997), um hipertexto é regido por seis princípios:

1. metamorfose: constante reconstrução;

2. heterogeneidade: as associações são as mais variadas possíveis;

3. multiplicidade e encaixe das escalas: cada nó leva a infindáveis redes, em escalas cada vez maiores, como em um esquema fractal;

4. exterioridade: o crescimento - ou decrescimento - se dá de fora, sob a influência de fatores externos, de novas conexões, de novas reconstruções;

5. topologia: "a rede não está no espaço, ela é o espaço", assim, todas as conexões se dão por proximidade; é uma questão de caminhos a seguir, caminhos estes que podem ser escolhidos a critério do leitor;

6. mobilidade dos centros: não há um centro definido na rede, mas infinitos centros, a partir dos quais continuamente se estendem novas ramificações.

Ainda para Lévy (1997), o hipertexto é "um conjunto de nós ligados por conexões" em que "os itens de informação não são ligados linearmente, como em cordas com nós, mas cada um deles, ou a maioria, estende suas conexões em estrela, de modo reticular". Esses nós remetem a informações variadas, muitas vezes imprevisíveis, permitindo construção de conhecimento de maneira muito similar à forma como naturalmente se desenvolvem nossos próprios esquemas mentais, "não mais em páginas, mas em dimensões superpostas que se 
interpenetram e que podemos compor e recompor a cada leitura" (RAMAL, 2002).

Com base em todas essas reflexões e, ao considerar que o motor do trabalho seria a investigação dos processos de interação para, em oportunidade futura, aproveitar a experiência e os conhecimentos adquiridos a fim de desenvolver um curso mais amplo e aprofundado que realmente contemplasse as quatro habilidades comunicativas e permitisse um desenvolvimento pleno dos estudantes no âmbito da língua alvo, decidi que me restringiria a trabalhar com um curso de leitura instrumental em língua espanhola e que esse curso estaria composto por apenas seis unidades. A primeira seria uma unidade para sondagem de conhecimentos prévios, com um texto de divulgação científica de nível alto de dificuldade acompanhado do respectivo questionário, atividade que seria repetida na última unidade, com um texto de mesmo gênero, ainda que de conteúdo diverso, e cujo objetivo seria avaliar um possível progresso dos alunos ao longo da breve experiência do curso. As demais unidades seriam compostas da seguinte maneira:

- Unidade 2: texto de divulgação científica (nível básico) e questionário;

- Unidade 3: biografia (nível básico) e questionário;

- Unidade 4: texto de e-mail (nível intermediário) e questionário;

- Unidade 5: anedotas (nível intermediário) e questionário.

Os níveis de dificuldade atribuídos a cada texto foram avaliados a partir das normas estabelecidas no Marco Común Europeo de Referencia para las Lenguas (CONSEJO DE EUROPA, 2002). Tratase de instrumento disponível à época, muito embora seus critérios hoje possam ser discutidos, já que documentos semelhantes têm surgido na América Latina com um enfoque mais específico no grupo humano que aqui habita. Consideram-se, aqui, como de nível básico os textos mais curtos e simples, com linguagem mais próxima ao cotidiano; de nível médio são os textos mais longos, que abordam temas contemporâneos e espelham diferentes pontos de vista; por fim, como nível alto ou avançado, estão os textos longos e complexos, muitas vezes utilizando linguagem especializada e técnica.

Três aspectos, porém, ainda precisavam ser levados em consideração em termos de elaboração das unidades didáticas: 
1. Que textos seriam postos à disposição dos estudantes?

2. Que conteúdos e explicações complementares poderiam ser úteis para um entendimento pelo menos razoável dos textos?

3. Que tipos de exercícios e questões seriam pertinentes para a melhor compreensão dos textos?

Cada uma dessas perguntas será respondida na próxima seção.

\section{Para trabalhar com textos e deficiência visual}

O primeiro passo do trabalho foi a escolha dos textos. Como havia optado por organizar a unidade inicial e a unidade final como unidades de controle, decidi que seria adequado que os textos das duas unidades pertencessem ao mesmo gênero e tivessem níveis de dificuldade semelhantes. Assim, escolhemos dois textos de divulgação científica de nível médio, intitulados, respectivamente: Comienza a comercializarse un bastón electrónico para ciegos e Un equipo de la Universidad de Málaga desarrolla pantallas de ordenador táctiles para ciegos. Ambos extraídos do site Tendencias 21 (www.tendencias21.net), revista eletrônica especializada em tecnologias. $O$ texto da unidade 2 acabou seguindo a mesma linha, já que seria a oportunidade de dar uma visão mais didática à leitura de textos científicos, efetivamente trabalhando e buscando desenvolver a habilidade da leitura em língua espanhola. Esse texto tinha como título Desarrollan un dispositivo para que los niños ciegos puedan "oir" los colores e foi retirado do site Top Noticias (www.topnoticias.com).

Para a biografia da unidade 3 , junto com a equipe que esteve envolvida no projeto, busquei o tema mais familiar possível e daí a ideia de utilizar uma brevíssima narrativa sobre a vida de Louis Braille. Até então, como se pode ver, havíamos dado prioridade a temas que estivessem relacionados diretamente aos deficientes visuais. Pareceume adequado, entretanto, ampliar o escopo das possibilidades e utilizar, nos dois textos seguintes, elementos diferentes. Assim, o texto de e-mail que utilizamos para a unidade 4 trazia um diálogo entre pai e filha, uma troca legítima de e-mails que foi cedida para o curso. O pai, espanhol vivendo no Brasil, envia notícias à filha que vive em Mallorca, que replica e, por fim, recebe uma tréplica. Nesse texto, nada foi tratado sobre deficiência. O texto seguinte era, na verdade, um conjunto de anedotas, 
com uma linguagem cheia de expressões coloquiais e com forte apelo cultural.

Como a leitura on-line, para um deficiente visual, só acontece com o uso de sintetizadores de voz ou da audição de arquivos sonoros e, ao considerar a opinião geral negativa sobre as vozes mecanizadas dos softwares, optamos por gravar todo este material em áudio. Os alunos tinham a opção de ler os textos por meio da síntese de voz ou a partir da leitura de um voluntário, que era gravada e cujo arquivo era disponibilizado no ambiente digital em que se desenvolveu o curso.

Definidos e gravados os textos, minha equipe e eu passamos a nos preocupar com as informações complementares que poderiam ajudar no entendimento desses textos. $\mathrm{Na}$ literatura a respeito de leitura instrumental, sempre se aconselha que os alunos sejam estimulados a prestar atenção nas ilustrações, fotos, gráficos etc. normalmente presentes. Também se sugere a exploração dos títulos, subtítulos, cabeçalho, da estrutura do texto, enfim, inúmeros elementos visuais que permitem, na maioria das vezes, fazer a diferenciação entre um poema e uma receita culinária, por exemplo, e ativar os conhecimentos prévios do leitor, preparando-o para o que irá ler (GIOVANNINI et al, 1996). A utilização desses recursos gráfico-visuais são fundamentais quando se trata de desenvolver técnicas de leitura como, por exemplo, o skimming - leitura rápida em busca da ideia geral - e o scanning busca de informação específica do texto (PAIVA, 2005). Na explicação dessas técnicas, aliás, sempre subjaz a ideia de olhos que passeiam sobre o texto para encontrar elementos específicos. Para a pessoa cega, entretanto, o uso de recursos visuais evidentemente é impraticável. Fomos buscar, então, na literatura da área, conceitos sobre leitura que nos pudessem ajudar a encontrar outros recursos que colaborassem com o processo de interpretação de textos, recursos que dispensassem o uso de elementos visuais. Nossa primeira referência foi Kintsch.

Walter Kintsch (1998), ao escrever sobre a aprendizagem a partir da leitura de textos, inicia sua reflexão com a pergunta "O que faz de alguém um bom leitor?”. Para o autor, a resposta não é simples, uma vez que leitores fluentes, em determinadas circunstâncias, podem ter sérias dificuldades para compreender um texto, enquanto leitores menos hábeis, mas com conhecimentos específicos sobre determinado assunto, podem compreender rapidamente um texto em tema que domina. A 
partir disso, defende que há alguns fatores importantes a se levar em conta para que se possa considerar alguém um bom leitor. A um desses fatores dá o nome de conhecimento do domínio, ou seja, da informação prévia a respeito do assunto. Para ele, ter uma ideia geral do tema abordado poderia compensar dificuldades na leitura. Ainda que isso fosse dispensável para leitores proficientes poderia ser importante para novos leitores ou, no nosso caso, leitores em uma nova língua. Essa reflexão e a impossibilidade de usar recursos visuais nos levaram a colocar, antes de cada texto, uma pequena explicação sobre o gênero que seria trabalhado, a título de introdução e com a finalidade de ativar conhecimentos anteriores dos estudantes, ao trazer à mente possíveis leituras prévias na mesma linha, conforme segue:

Agora, estudaremos mais detidamente um texto de divulgação científica. Esse tipo de texto resulta do encontro entre dois gêneros discursivos: o jornalístico e o científico. Isso significa que o objetivo de quem o escreve é permitir ao público leigo acesso a informações que, por sua natureza, geralmente estão circunscritas a um pequeno grupo de especialistas. Por isso, esse gênero textual busca divulgar os temas que lhe correspondem com um vocabulário mais próximo ao de uso cotidiano, evitando, sempre que possível, os jargões próprios de um determinado círculo restrito de pessoas. São textos muitas vezes encontrados nas sessões científicas de jornais e em revistas como Superinteressante, Galileu etc. (OYE! [s.d.])

Outro fator abordado por Kintsch na obra citada é a habilidade de decodificação. Sobre isso, o autor, com base em Perfetti (1985), afirma que bons leitores são bons decodificadores, capazes de reconhecer palavras muito mais rapidamente que leitores não hábeis. A rápida decodificação seria importante porque deixaria livres os recursos cognitivos necessários para que o leitor possa interpretar rápida e adequadamente o texto. Isso estaria relacionado, também, à amplitude de vocabulário. Maior vocabulário, mais rapidez na decodificação e, por consequência, mais rapidez na interpretação. Assim, enquanto os leitores hábeis conseguem interpretar um texto a partir da decodificação direta, leitores não hábeis necessitam, muitas vezes, do sentido 
contextual, o que torna o processo mais lento. Ao transpor isso para o aprendizado de uma língua estrangeira, especialmente no contexto de línguas próximas como o português e o espanhol, percebe-se a importância de aquisição de um vocabulário mínimo para a interpretação dos textos. De fato, não se pode negar que a língua portuguesa e a espanhola compartilham muitas palavras e muitas estruturas. Por outro lado, há palavras e expressões que são verdadeiras armadilhas para o leitor inexperiente. Com base nisso, outra decisão tomada foi a de incluir nas atividades do curso breves explicações e exemplos sobre palavras heterossemânticas (com escrita ou pronúncia semelhante entre ambos os idiomas, mas de significados diferentes), heterogenéricas (com variação de gênero entre português e espanhol) e heterotônicas (com variação de tonicidade), além de algumas expressões idiomáticas. Também para facilitar a decodificação dos estudantes, optamos por colocar ao final de cada texto um pequeno vocabulário, contendo as palavras e expressões que julgamos ser de mais difícil entendimento.

Por se tratar de um curso de curtíssima duração, pareceu-nos adequado não saturar os estudantes com informações sobre o idioma, restringindo-nos ao básico para que eles pudessem desenvolver suas atividades de leitura. Definida essa estratégia, passamos a nos preocupar com os tipos de exercícios e questões que poderíamos desenvolver a fim de avaliar se os estudantes conseguiriam entender os textos propostos. Com relação ao formato, optamos imediatamente por questões de tipo dissertativo, em que os participantes teriam condições de expressar-se livremente, o que também nos proporcionaria a oportunidade de ter uma visão mais clara de sua compreensão e de seu progresso. Em todas as unidades, optamos por começar com perguntas de ordem geral, ou, como diz Paiva (2005), perguntas envolvendo "o registro do texto, ou seja, a atividade social e objetivos do texto, a relação entre o escritor e seus leitores, e o estilo do texto". Questões como: qual o tema central do texto, de onde foi retirado, seus propósitos, seu público-alvo, seu autor etc. Essas questões serviriam como instrumento para situar os leitores no universo do material lido, a fim de que pudessem passar, em seguida, a perguntas mais pontuais de compreensão do conteúdo, indo do geral ao específico, além de perguntas de entendimento de aspectos subjetivos, inclusive de elementos linguísticos (GIOVANNINI et al., 1996). 
Este, portanto, foi o encaminhamento geral que se conseguiu dar para desenvolver um curso de leitura on-line para deficientes visuais. E quais foram os resultados? Veremos isso em seguida.

\section{Considerações finais}

Após todas essas reflexões sobre leitura e muitas mais envolvendo os aspectos técnico-tecnológicos e contando com o apoio de uma dedicada equipe de voluntários, ao longo do último trimestre de 2008 foi possível desenvolver um curso de leitura on-line em língua espanhola voltado diretamente para pessoas com deficiências visuais. Contamos com cerca de 30 alunos de todos os cantos do Brasil, inclusive, de Portugal. Os resultados foram excelentes. Mesmo aqueles alunos com mais dificuldades conseguiram construir conhecimento significativo sobre a língua espanhola.

Com o êxito da experiência, novas iniciativas estão sendo implementadas. O grande objetivo, agora, é a elaboração de um curso completo de língua espanhola, envolvendo as quatro habilidades linguísticas. Para isso, novas pesquisas estão sendo feitas e, evidentemente, novos desafios vão surgindo. Espera-se que no primeiro semestre de 2011, um curso de extensão on-line em língua espanhola para deficientes visuais tenha início na Universidade Federal de Santa Maria. Com a experiência e a prática que isso proporcionará, espera-se, com o tempo poder estender esta iniciativa para o nível da graduação.

Algo que ainda faz falta, entretanto, é o engajamento de professores que trabalhem com outras línguas estrangeiras. O trabalho com línguas próximas, como é o caso do espanhol e do português, tem características bastante definidas e distintas daquele realizado com línguas afastadas, como o inglês, por exemplo. Uma expectativa que se tem é sobre a possibilidade de ampliar o escopo das pesquisas e estendê-las para outras línguas estrangeiras. Pelo que se vê, apesar dos enormes desafios, os resultados são compensadores e os estudantes com deficiência visual sabem retribuir os esforços de pesquisa com uma participação ativa que resulta em uma troca de experiências importante para aperfeiçoar qualquer iniciativa neste sentido.

Por fim, remeto-me ao título deste texto, lembrando que, apesar de qualquer dificuldade, a leitura é muito mais que uma questão de 
visão: é preciso ter percepção, é preciso sentir o texto para compreendêlo e isso, a condição de sermos humanos nos permite, independentemente de qualquer obstáculo.

\section{Referências}

CARVALHO, J. O. F. Soluções tecnológicas para viabilizar o acesso do deficiente visual à Educação a Distância no Ensino Superior. 2001. 150f. Tese (Doutorado em Engenharia Elétrica) - Universidade Estadual de Campinas, Campinas.

CONSEJO DE EUROPA. Marco común europeo de referencia para las lenguas: aprendizaje, enseñanza, evaluación. Madri: Grupo Anaya S. A., 2002.

FONTANA, M. V. L.; VERGARA NUNES, E. L. Audioteca Virtual de Letras: tecnologia para inclusão. RENOTE - Revista Novas Tecnologias na Educação, Porto Alegre, v. 3, n. 2, p. 1-9, nov. 2005.

GIOVANNINI, A.; MARTÍN PERIS, E.; RODRÍGUEZ, M.; SIMÓN, T. Profesor en acción 3: destrezas. Madrid: Edelsa, 1996.

KINTSCH, W. Learning from text. In: Comprehension: a paradigm for cognition. Cambridge: Cambridge University Press, 1998.

LEFFA, V. J. A aprendizagem de línguas mediada por computador. In: - (Org.). Pesquisa em Lingüística Aplicada: temas e métodos. Pelotas: Educat, 2006. p. 11-36.

LÉVY, P. As tecnologias da inteligência: o futuro do pensamento na era da informática. Rio de Janeiro: Editora 34, 1997.

MON, F. Algunas definiciones en torno al concepto de discapacidad visual. Periódico El Cisne, Buenos Aires, out. 1998.

MORAN, J. M. Tendências da educação online no Brasil. In: RICARDO, E. J. (Org.). Educação Corporativa e Educação a Distância. Rio de Janeiro: Qualitymark, 2005. 
OYE! Espanhol para professores. [s.d.] Disponível em: <http:// sites.google.com/site/oyecurso/uni02>. Vários acessos.

PAIVA, V. L. M. O. Desenvolvendo a habilidade de leitura In:

(Org.). Práticas de ensino e aprendizagem de inglês com foco na autonomia. Belo Horizonte: Faculdade de Letras da UFMG, 2005. p. 129-147.

. O lugar da leitura na aula de língua estrangeira. Vertentes, $n$. 16, p. 24-29, jul./dez. 2000.

PARAQUETTT, M. Da abordagem estruturalista à comunicativa: um esboço histórico do ensino de Espanhol Língua Estrangeira no Brasil. In: TROUCHE, A. L. G.; REIS, L. de F. (Orgs.). Hispanismo 2000. Brasília: Ministerio de Educación, Cultura y Deporte; Associação Brasileira de Hispanistas, v. 1, 2001. p. 186-194.

RAMAL, A. C. Educação na cibercultura: hipertextualidade, leitura, escrita e aprendizagem. Porto Alegre: Artmed, 2002.

SANTAROSA, L. M. C.; SONZA, A. P. Ambientes virtuais digitais: acessibilidade aos deficientes visuais. Revista Novas Tecnologias na Educação, Porto Alegre, v. 1, n. 1, 2003.

SEDYCIAS. J. O que é espanhol instrumental? 2002. Disponível em <http://www.sedycias.com/instrument_01s.htm>. Acesso em: 5 mar. 2008.

UR, P. A course in language teaching: practice and theory. Cambridge: Cambridge University Press, 1996.

VEEN, W.; VRAKKING, B. Homo zappiens: educando na era digital. Porto Alegre: Artmed, 2009. 